\title{
EFFECT OF INORGANIC ALTERNATIVE SCOURING AGENTS ON STRUCTURE OF CELLULOSE/POLYESTER BLEND FABRIC
}

\author{
A. U. Barambu ${ }^{1 *}$, D. E. A. Boryo ${ }^{1}$, H. M Adamu ${ }^{1}$, K. M yahuza ${ }^{1}$, A. Abdulkadir ${ }^{2}$ \\ ${ }^{1}$ Department of Chemistry, Abubakar Tafawa Balewa University Bauchi, Bauchi State, Nigeria \\ ${ }^{2}$ Department of Chemistry, Gombe State University, Gombe State, Nigeria \\ *Corresponding author e-mail: aubnabiu@gmail.com, +2348032985884 \\ Received 04 June 2020; accepted 01 July 2020, published online 06 July 2020
}

\begin{abstract}
In this research, a structural modification for a cellulose/polyester blend has been carried out using $\mathrm{NH}_{4} \mathrm{OH},\left(\mathrm{NH}_{4}\right)_{2} \mathrm{C}_{2} \mathrm{O}_{4}$ and liquid $\mathrm{NH}_{3}$ which are environmentally friendly alternative scouring agents with $\mathrm{NaOH}$ as control. The scouring process was carried out on the samples with these alternative agents. Investigation into structural modification of cellulose/polyester blend fabric using $\mathrm{NH}_{4} \mathrm{OH},\left(\mathrm{NH}_{4}\right)_{2} \mathrm{C}_{2} \mathrm{O}_{4}$ and liquid $\mathrm{NH}_{3}$ and its structural characterization with X-ray diffraction was carried. The results showed the inferences variation in the crystallinity index of scoured samples from (3.21-65.30\%), the crystallite size of scoured samples $(1.9-15 \mathrm{~nm})$ in the crystalline region and $(7-20 \mathrm{~nm})$ in the amorphous region, inter-planar spacing of the scoured samples $(0.340-0.350 \mathrm{~nm})$ of the crystalline region and $(0.350-0.340 \mathrm{~nm})$ of the amorphous region and number of crystalline planes of the scoured samples is (3-11) of the cellulose/polyester blend fabric samples via $\mathrm{X}$-ray diffraction studies. Among these alternative agents $\left(\mathrm{NH}_{4}\right)_{2} \mathrm{C}_{2} \mathrm{O}_{4}$ and $\mathrm{NH}_{4} \mathrm{OH}$ showed better interaction with both amorphous and crystalline regions of the cellulose/polyester blend fabric samples without loss in crystallinity when used as scouring agents, and the possibilities of being a superior alternative with significant effect on the structures of the cellulose/polyester blend, while the other samples showed possibilities of being highly competitive with the conventional agent.
\end{abstract}

Keywords; Cellulose, Inorganic, Polyester, Structure, Scouring Agents

\section{Introduction}

Cellulose today is the most used textile fibre in the world. Its current share is 56 percent for all fibres used for fashion and home furnishings in market [1]. Cellulose is a carbohydrate which is the chief component of the cell walls of plants and is found in wood and in cotton, linen, jute, hemp, leaves and stem fibers [2]. It is a basic raw material in the manufacture of rayon, acetate and triacetate fibers [3], and contains $44.4 \%$ carbon, $6.2 \%$ hydrogen and $49.4 \%$ oxygen. The elementary unit of a cellulose macromolecule is anhydro-d-glucose $\mathrm{C}_{6} \mathrm{H}_{10} \mathrm{O}_{5}$, which is repeated severally in the cellulose molecules. Hence, it is a high molecular mass compound with dglucose anhydrides of $\beta$-form are interconnected by 1-4 glycosidic linkage [4].

Polyester fibres are synthetic fibre with a long chain polymer composed of at least $85 \%$ by weight of an ester of dihydric alcohol and terephthalic acid [5].
Dihydric alcohol like ethylene glycol react with an aromatic acid like terephthalic acid with two acid groups, the reaction can take place under suitable condition to make polymeric esters "polyester". One $\mathrm{OH}$ group of the alcohol molecule reacts with one $\mathrm{COOH}$ group of the terephthalic acid and the remaining $\mathrm{COOH}$ group of the acid reacts with another alcohol, thus react alternatively with alcohol and acid to form a chain of polymeric polyester $[6,4]$.

Cellulose/polyester blend fabric is the combination of natural and synthetic fabrics so that the good quality and properties are emphasis and a poor quality and properties are minimize. The blends of cellulose/polyester have developed into one of the most important textile fabric group. This is due to the unique properties of the fabric which has the potential to be similar in comfort performance to cellulose, but, owing to the presence of the polyester, be of a more stable price (possibly cheaper) than 
cellulose and possess excellent easy-care properties [7]. Today, everyone needs better quality fabric products with improved performance at an affordable rate [8].

The modifications of these fabrics structure can be achieved by substituting the protons in the hydroxyl groups of cellulose to a varying extent using various substituents in production processes and chemical treatments $[9,10]$. However, there was no detailed information on the structural changes (modification) in the fabrics. Hence, an investigation of this study is undertaken to know the actual changes that occurred on the structural property related. Also, to establish whether the modifications are on physical or chemical changes by the alternative agents on the fabrics during the scouring processes using $\mathrm{X}$-ray diffraction.

\section{Materials and Methods}

\section{Sample collection and preparation}

The sample of cellulose/polyester blend fabric (3.5:6.5) was purchased from Central Market Bauchi, Bauchi State, Nigeria. The sample was cut into pieces of dimension $10 \mathrm{~cm}$ length by $10 \mathrm{~cm}$ width and kept in the laboratory prior to chemical treatment.

Scouring process (alternative scouring agents)

The pieces of fabrics samples were immersed into five different beaker containing equal volumes of $1 \%, 2 \%, 3$ $\%, 4 \%$ and $5 \% \mathrm{NaOH}$ solution after boiling for 5 minute. The samples were then allowed to boil for one hour using glass rod to completely immerse the fabrics into the solution. The fabrics were rinsed with cold over flowing tap water. 1 $\%$ acetic acid was used to neutralize the fabric followed by washing in $2 \%$ detergent solution. Then the fabric was rinsed with distilled water and dried in the laboratory at room temperature. The same procedure was repeated for liquid ammonia, ammonium hydroxide and ammonium oxalate for the cellulose/polyester samples. $1 \%$ sodium hydroxide solution or $1 \%$ acetic acid was used to neutralize the different scouring agents [9].

\section{Bleaching process (alternative scouring agents)}

All the scoured samples were bleached using $4 \mathrm{~g} / \mathrm{l}$ sodium chlorite $\left(\mathrm{NaClO}_{2}\right)$ solution according to the procedure described by [11] and employed by [12, 13]. The $\mathrm{pH}$ of the sample was monitored using concentrated nitric acid $\left(\mathrm{HNO}_{3}\right)$ at a $\mathrm{pH}$ of 3 during preparation. The sodium chlorite solution was boiled on a hot plate for 5 minutes in a beaker, and the scoured fabric was immersed in the solution and allowed to boil for 3 hours at a temperature of $75^{\circ} \mathrm{C}$ after which it was washed in a hot water, and neutralized with $5 \%$ acetic acid, then washed with $2 \%$ detergent solution and finally rinsed with cold water and dried in the laboratory at room temperature for 45 minutes.

\section{Mercerization process (alternative scouring agents)}

In this research work mercerization process was carried out using concentrated solutions of $22 \%$ $\mathrm{NaOH}$ at a temperature $5^{\circ} \mathrm{C}$ for 45 minutes.

\section{Preparation of samples}

Fabric samples were conditioned in an oven at $80^{\circ} \mathrm{C}$ for 48 hours to remove moisture present at the surface and absorbed within the fabric samples. The samples were then blended using a manual blender.

\section{XRD analysis of samples}

Powder x-ray diffraction analysis was used to determine the crystalline and amorphous nature of the fabric samples. Powder XRD data were collected using an X-ray diffractometer (Bruker AXS D-8 Advance, Germany), equipped with $\mathrm{Cu}$ radiation source (wavelength $\lambda=1.54056$ $\AA$ ) operating at $40 \mathrm{kV}$ and $40 \mathrm{~mA}$ and a Vantec detector.

The crystallinity index was estimated in this study using the equation adopted by [14] as shown below in Equation 1.

$\mathrm{CI}(\%)=\mathrm{x} 100 \%$

Where; $I_{c+a}$ is the intensity of the crystalline and amorphous peak, $I_{a}$ is the intensity of the amorphous peak. 
The crystallite size was determined using scherrer's formula which is as shown below;

Crystal size (D) $(\mathrm{nm})=0.89 \lambda / \beta \cos \theta$ (2)

The inter-planar spacing was determined using Bragg's formula [14] Equation (3);

$\mathrm{n} \lambda=2 \mathrm{~d} \sin \theta$, where $\mathrm{n}=1$.

Interplanar spacing (d-spacing) $(\mathrm{nm})=$ $\mathrm{n} \lambda / 2 \sin \theta$

Where; $\lambda$ is the $\mathrm{X}$-ray wavelength $(0.154$ $\mathrm{nm}), \quad \beta$ is the angular width at half maximum intensity determine with the aid of Gaussian fit of the peaks on the diffractograms of the samples and $\theta$ is the Bragg angle.

\section{Results and Discussion}

Effect of inorganic alternative scouring agents on percentage crystallinity index of cellulose/polyester blend fabric: The primary purpose of scouring pretreatment in fabric production is to remove impurities which include fat, oil, wax and nitrogenous matters that may interfere with the dyeing, finishing operation and mechanical properties of the fabric. In this study, the morphological transformation in cellulose/polyester blend fabric during scouring was investigated using 1 to $4 \% \mathrm{NaOH}$ (Figure 1a), 1 to $4 \%$ liquid $\mathrm{NH}_{3}$ (Figure 1b), 2 to $5 \% \mathrm{NH}_{4} \mathrm{OH}$ (Figure 1c) and 1 to $4 \%\left(\mathrm{NH}_{4}\right)_{2} \mathrm{C}_{2} \mathrm{O}_{4}$ (Figure 1d). The $2 \theta$ in appendix 5 shows broadness between 10 to $20^{\circ}$ which is an indication that the blend is amorphous, while the sharp peak between 10 and 20 in figure 20 under appendix III indicates crystallinity in the blend. The crystallinity index (41.89$65.30 \%$ ) of the fabric increased on scouring with increase in $\mathrm{NaOH}$ concentration except with $2 \% \mathrm{NaOH}$. Boryo established that, this could be an indication of improved mechanical strength of the fabric as the crystalline region had more contribution to mechanical strength than amorphous region [9]. The observed variation in crystallinity index could have resulted from either dissolution of the amorphous region or phase transition in the morphology of the scoured fabric, and it was confirmed.
Liquid $\mathrm{NH}_{3}$ was able to interact with both the amorphous and the crystalline region as apparent from the crystallinity index (3.21-50.41\%) of the fabric treated (figure 1b). The $2 \theta$ in figure 21 in appendix III shows broadness between 10 to $20^{\circ}$ which is an indication that the blend is amorphous. The crystallinity index decreased to $0 \%$ when 3 wt. \% liquid $\mathrm{NH}_{3}$ was employed for the scouring process. Similarly, with 2 wt.\% treatment, the crystallinity index was reduced but not to $0 \%$. This observation suggested that liquid $\mathrm{NH}_{3}$ interacted in a different manner when compared with that of $\mathrm{NaOH}$. Unlike $\mathrm{NaOH}$, liquid $\mathrm{NH}_{3}$ was able to remove the impurities available in amorphous region more than crystalline regions of the cellulose/polyester blend. This brought about the observable reduction in the crystallinity index with increase in wt.\% of $\mathrm{NH}_{3}$ used in the scouring pretreatment. There was a significant variation in the crystallinity index from $1 \%$ to $5 \%$ (27.92 - 60.04\%) (Figure 4c) of polyester fabric samples scoured with $\mathrm{NH}_{4} \mathrm{OH}$ with the highest value observed at $4 \%$.

In a similar version to liquid $\mathrm{NH}_{3}$, $\left(\mathrm{NH}_{4}\right)_{2} \mathrm{C}_{2} \mathrm{O}_{4}$ was able to interact with both the amorphous and the crystalline region as shown from the crystallinity index $(0.06-54.25 \%)$ (Figure $4 d)$ of the polyester fabric blend samples treated. The crystallinity index decreased to $0.06 \%$ when 3 wt. $\% \quad\left(\mathrm{NH}_{4}\right)_{2} \mathrm{C}_{2} \mathrm{O}_{4}$ was employed for the scouring process. However, with $4 \mathrm{wt} . \%$ pretreatment, the crystallinity index increased to $54.25 \%$ higher than the control while with 2 wt.\% the crystallinity index was relatively constant with that of the control. This observations suggested that $\left(\mathrm{NH}_{4}\right)_{2} \mathrm{C}_{2} \mathrm{O}_{4}$ interacted with the treated cellulose/polyester blend, fabric by penetrating both amorphous and crystalline regions like liquid $\mathrm{NH}_{3}$, as the penetration of the crystalline region brought about the observable reduction in the crystallinity index. 

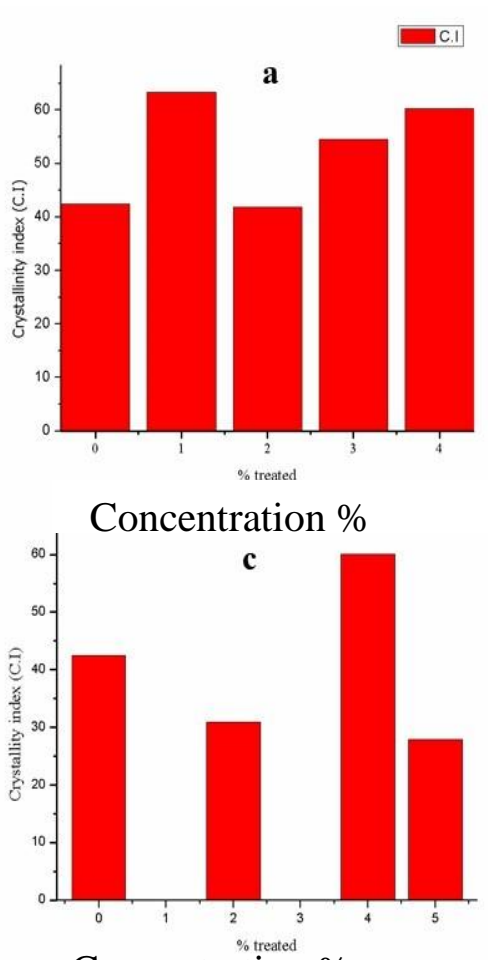

Concentration $\%$

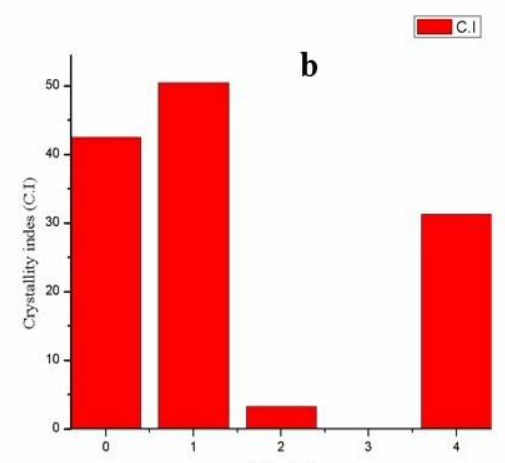

Concentration \%

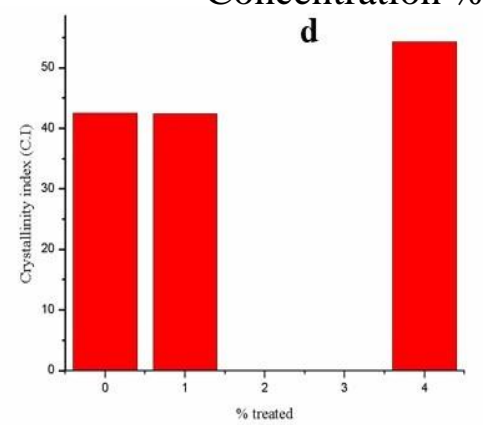

Concentration

Fig. 1: Percentage crystallinity index for (a) $\mathrm{NaOH}$, (b) Liquid $\mathrm{NH}_{3}$, (c) $\mathrm{NH}_{4} \mathrm{OH}$, and (d) $\left(\mathrm{NH}_{4}\right)_{2} \mathrm{C}_{2} \mathrm{O}_{4}$ scouring of cellulose/polyester blend fabric.

Effect of inorganic alternative scouring agents on d-spacing: The low concentrated $\mathrm{NaOH}(1-4 \mathrm{wt} \%)$ solution used in the scouring process contained hydrated species $\left(\mathrm{NaOH} \cdot \mathrm{xH}_{2} \mathrm{O}\right)$ with large hydrodynamic radius, which could only penetrate the amorphous phase of the treated fabric. This could be easily noted in the difference in the inter-planar spacing $(0.350-0.340 \mathrm{~nm})$ of the amorphous and the crystalline region (Figure 2a).

The variation in the inter - planar spacing (Figure 2b) in the fabric scoured with liquid $\mathrm{NH}_{3}$ was higher than that of fabric scoured with $\mathrm{NaOH}$, an indication of improved interaction with the crystalline region by liquid $\mathrm{NH}_{3}(0.348-0.340 \mathrm{~nm})$, this could however lead to a compromise in the mechanical strength of the fabric. However, the interaction was more pronounced in the amorphous region as the inter-planar spacing (Figure 2c) of the crystalline region remained relatively constant $(0.340 \mathrm{~nm})$, an indication of higher resistance to penetration of the scouring agent. In comparison with $\mathrm{NaOH}$ and liquid $\mathrm{NH}_{3}, \mathrm{NH}_{4} \mathrm{OH}$ as a scouring agent was able to penetrate both amorphous and crystalline regions of the fabric although with less degree in the crystalline region. This showed better scouring properties without much influence on the morphology of the fabric thereby preserving the mechanical strength of the fabric. This observation aligned with findings of [9] on mechanical properties of alternative scouring agents where fabrics scoured with $\mathrm{NH}_{4} \mathrm{OH}$ was reported to show improved mechanical property.

The variation in the inter-planar spacing (Figure 2d) in both crystalline region $(0.344-0.350 \mathrm{~nm})$ and amorphous regions was similar to liquid $\mathrm{NH}_{3}$ however a steady progression was observed in the inter-planar spacing of the crystalline region compared to that of amorphous regio 

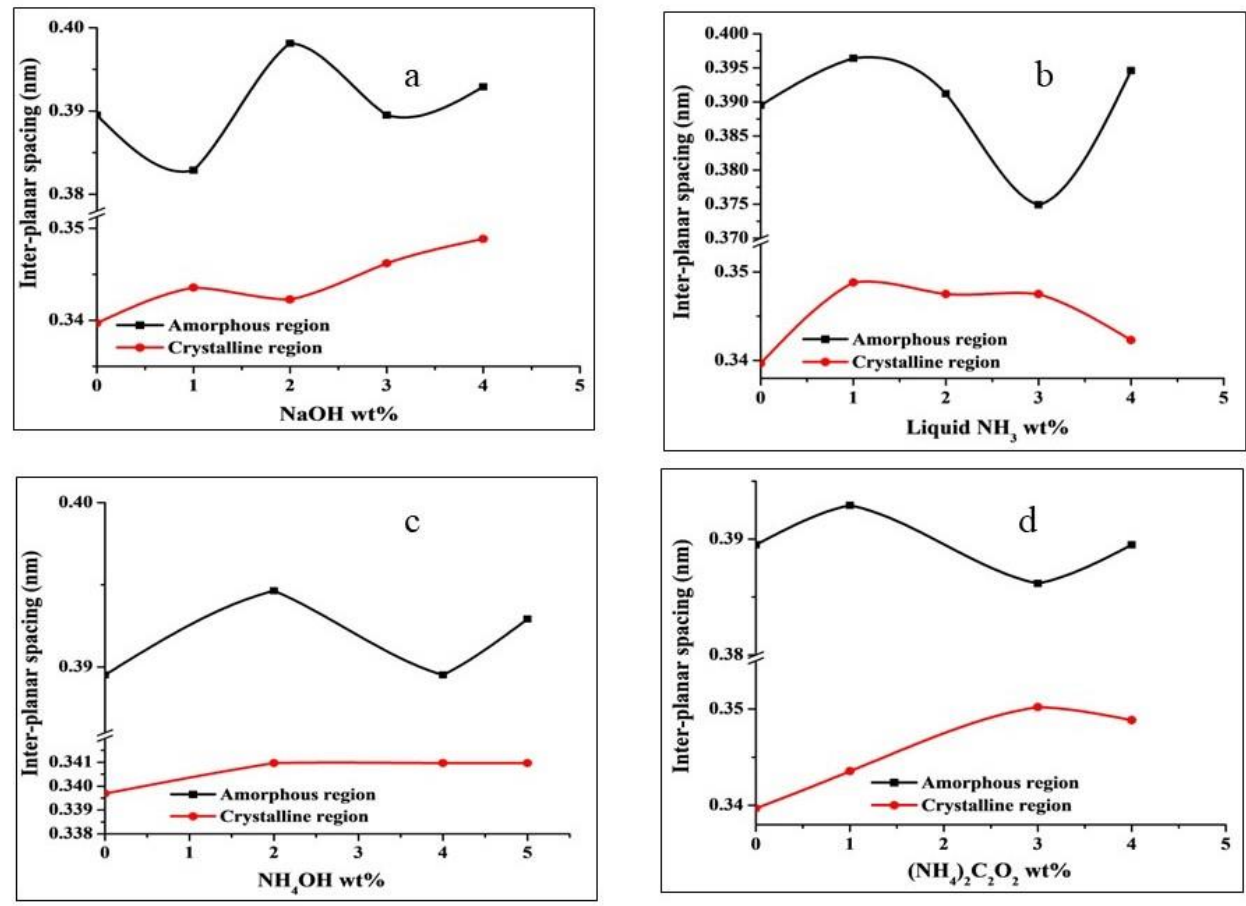

Fig. 2: The inter-planar spacing (d-spacing) for (a) $\mathrm{NaOH}$, (b) Liquid $\mathrm{NH}_{3}$ (c) $\mathrm{NH}_{4} \mathrm{OH}$ and (d) $\left(\mathrm{NH}_{4}\right)_{2} \mathrm{C}_{2} \mathrm{O}_{4}$ Scouring of Cellulose/Polyester Blend Fabric.

Effect of inorganic alternative scouring agents on crystallite size: The crystallite size (Figure 3a) of the amorphous region showed a reverse trend compared to that of the crystalline region $(6.0-8.0 \mathrm{~nm})$ where the crystallite size increased and stabilized at high concentration of $\mathrm{NaOH}$ while the crystallite size of the amorphous region decreased with increase in wt.\% of $\mathrm{NaOH}$ and from 2 wt. $\%$, the crystallite size increased. This variation confirmed that conventional scouring process had stronger influence on the structural modification of the amorphous region compared to the crystalline region of the cellulose/polyester blend fabric. This agrees with the findings of [5, 9].

The observed downward trend in crystallite size (7.0 - $14.0 \mathrm{~nm})$ (Figure 3b) of the amorphous region of the fabric scoured with increase in liquid $\mathrm{NH}_{3}$ could suggest that some of the amorphous phase was affected just as the crystalline region was also affected in the reverse trend. This showed that liquid $\mathrm{NH}_{3}$ affected both amorphous and crystalline regions of the cellulose/polyester blend fabric in a competitive manner compared to $\mathrm{NaOH}$ that affect more with the amorphous region. This could have resulted in the improved dyeing properties of cellulose/polyester blend scoured with liquid $\mathrm{NH}_{3}$ as reported by [5]

The trend observed in the crystallite sizes $(1.9-8.0 \mathrm{~nm})$ (Figure 3c) of both amorphous and crystalline regions in the fabric scoured with $\mathrm{NH}_{4} \mathrm{OH}$ showed that the scouring agent interacted in a similar manner with the samples in both regions.

An inverse trend was observed in crystallite size $(5.5-15.0 \mathrm{~nm})$ (Figure $3 \mathrm{~d}$ ) of the amorphous and crystalline regions of the fabric scoured with increase in $\left(\mathrm{NH}_{4}\right)_{2} \mathrm{C}_{2} \mathrm{O}_{4}$ suggesting that some of the amorphous region was affected just as the crystalline region was also affected in the reverse trend. This observation was similar to those observed in fabric scoured with liquid $\mathrm{NH}_{3}$ and $\mathrm{NaOH}$. This showed that scouring with $\left(\mathrm{NH}_{4}\right)_{2} \mathrm{C}_{2} \mathrm{O}_{4}$ could lead to fabric with intermediate properties of those scoured with $\mathrm{NH}_{3}$ and $\mathrm{NaOH}$ as observed by [9] in the optimum dry crease recovery. 

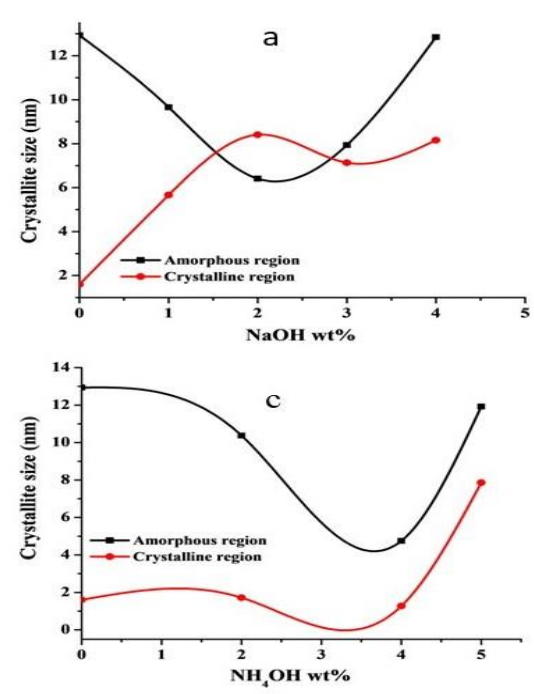

Fig. 3: The crystallite size for (a) $\mathrm{NaOH}$,

(b) Liquid $\mathrm{NH}_{3}$ (c) $\mathrm{NH}_{4} \mathrm{OH}$ and (d) $\left(\mathrm{NH}_{4}\right)_{2} \mathrm{C}_{2} \mathrm{O}_{4} \quad$ Scouring of

Cellulose/Polyester Blend Fabri

Effect of inorganic alternative scouring agents on number of crystalline planes: The effect of phase transition could also be observed in (Figure 4a) where notable changes were observed in the number of crystalline planes (6.0 - 11.0) with increase in concentration of the scouring agent. As the concentration of $\mathrm{NaOH}$

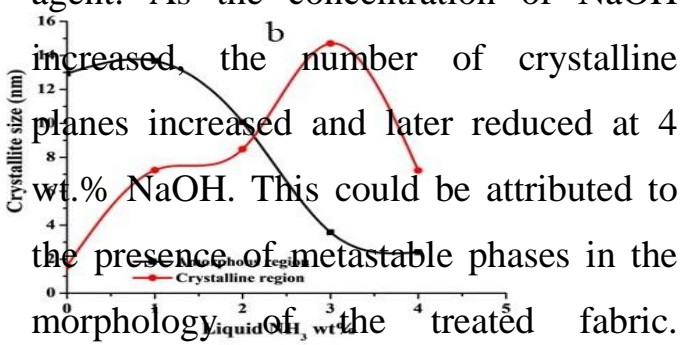
7ొariation in number of crystalline planes 要 15.0 - 7.0) (Figure/4b) with increase in 产 concentration of liquid $\mathrm{NH}_{3}$ used for scouring also suggested presence of

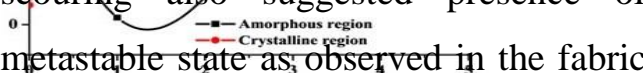

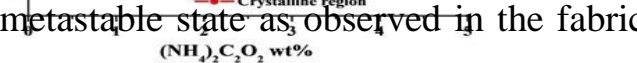
scoured with $\mathrm{NaOH}$ [11]. The crystalline phases were observed to be similar except at high concentration of $5 \mathrm{wt} . \% \mathrm{NH}_{4} \mathrm{OH}$, the number of crystalline planes (3.0 7.0) (Figure 4c) was relatively constant. Similarly, steady progression was observed in the variation in number of crystalline planes (3.0 - 7.0) (Figure 4d) with increase in concentration of $\left(\mathrm{NH}_{4}\right)_{2} \mathrm{C}_{2} \mathrm{O}_{4}$ used for scouring also suggested presence of metastable state as observed in the blend fabric scoured with liquid $\mathrm{NH}_{3}$ and $\mathrm{NaOH}$. 

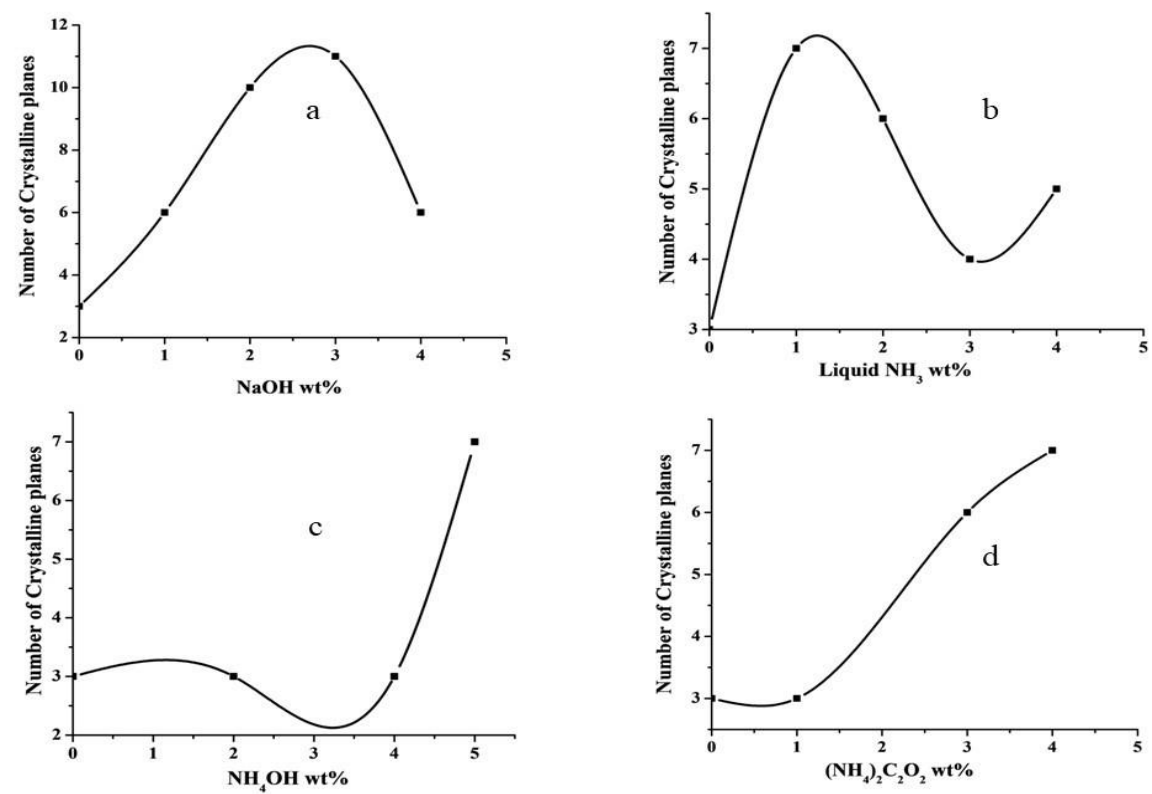

Fig. 4: The Number of Crystalline Planes for (a) $\mathrm{NaOH}$, (b) Liquid $\mathrm{NH}_{3}$ (c) $\mathrm{NH}_{4} \mathrm{OH}$ and (d) $\left(\mathrm{NH}_{4}\right)_{2} \mathrm{C}_{2} \mathrm{O}_{4}$ Scouring of Cellulose/Polyester Blend Fabric.

Optimum Conditions for Alternative inorganic Scouring Agents

Table 1: Optimum conditions for alternative scouring agents on percentage crystallinity index

\begin{tabular}{ll}
\hline Inorganic Scouring agent & $\begin{array}{l}\text { Percent } \\
\text { crystall } \\
\text { index }(\%\end{array}$ \\
\hline $2 \% \mathrm{NaOH}$ & 41.89 \\
$1 \%$ liq. NH & 50.41 \\
$4 \% \mathrm{NH}_{4} \mathrm{OH}$ & 60.04 \\
$4 \%\left(\mathrm{NH}_{4}\right)_{2} \mathrm{C}_{2} \mathrm{O}_{4}$ & 54.25
\end{tabular}

$4 \% \mathrm{NH}_{4} \mathrm{OH}$

$1 \%\left(\mathrm{NH}_{4}\right)_{2} \mathrm{C}_{2} \mathrm{O}_{4}$

0.340

0.344

Table 3: Optimum Conditions for Alternative Scouring Agents on Crystallite Size

\begin{tabular}{ll}
\cline { 2 - 3 } Scouring agent & $\begin{array}{l}\text { Crystallite size } \\
(\mathbf{n m})\end{array}$ \\
\hline $2 \% \mathrm{NaOH}$ & 8.0 \\
$1 \%$ liq. $\mathrm{NH}_{3}$ & 14.0 \\
$4 \% \mathrm{NH}_{4} \mathrm{OH}$ & 8.0 \\
$4 \%\left(\mathrm{NH}_{4}\right)_{2} \mathrm{C}_{2} \mathrm{O}_{4}$ & 15.0 \\
\hline
\end{tabular}

Table 4: Optimum Conditions for

Table 2: Optimum Conditions for Alternative Scouring Agents on d-spacing

\begin{tabular}{|c|c|c|c|}
\hline on d- & & & crystalline plane \\
\hline Scouring agent & $\begin{array}{l}\text { d-spacin } \\
(\mathbf{n m})\end{array}$ & $2 \% \mathrm{NaOH}$ & 10.0 \\
\hline $2 \% \mathrm{NaOH}$ & 0.340 & $5 \% \mathrm{NH}_{4} \mathrm{OH}$ & 7.0 \\
\hline $4 \%$ liq. $\mathrm{NH}_{3}$ & 0.340 & $4 \%\left(\mathrm{NH}_{4}\right)_{2} \mathrm{C}_{2} \mathrm{O}_{4}$ & 7.0 \\
\hline
\end{tabular}

Table 1 all the optimum condition of the scoured agent for percentage crystallinity index are higher than that of the control $(2 \% \mathrm{NaOH})$ Even though the d-spacing did not show much improvement compared to the control ( 0.340 or slightly higher, and 0.340 respectively) for the scouring agents as shown in Table 2. Table 3 and 4 all the optimum condition are higher than that of control with these all the alternative agent can computes with the control owing to it less hazardous effect and cheaper than $\mathrm{NaOH}$.

\section{Conclusion}

The scouring of cellulose/polyester blend fabric using alternative agents was carried out and the effect on the structures of the 
fabric ware evaluated using X-ray diffraction. Among these alternative agents, $\left(\mathrm{NH}_{4}\right)_{2} \mathrm{C}_{2} \mathrm{O}_{4}$ and $\mathrm{NH}_{4} \mathrm{OH}$ showed the possibilities of being a superior alternative with significant effect on the structures of the cellulose/polyester blend. It was confirmed that the modifications on the fabric were both physical and chemical changes. Therefore, these alternative agents should be engaged as scouring agents industrially for commercial purpose.

\section{References}

[1]. C. E. Wyman, B. E. Dale, R. T. Elander, M. Holtzapple, M. R. Ladisch and Y. Y. Lee (2005), Coordinated Development of Leading Biomass Pretreatment Technologies. Journal of Bioresource Technology, 96, 1959-1966.

[2]. F. Phillippe, L. Schacker, D. C. Adolphe, and C. Dacremon (2004), Textlile feeling: sensory analysis applied to textile goods. Textiles research journal, 70, 1066-1072.

[3]. D. Chiaramonti, A. M. Rizzo, V. Prussi (2011), 2nd generation lignocellulosic bioethanol: is torrefaction a possible approach to biomass pretreatment? Biomass Conversion and Biorefinery, DOI 10.1007/s13399-010-0001-z

[4]. D. E. A. Boryo (2016), CHM 356: Color and Textile Chemistry Lecture Note, Department of Chemistry, ATBU Bauchi.

[5]. D. E. A. Boryo, K. A. Bello, A. Q. Ibrahim, N. S. Gin, T. M. Dauda, and V. O. Elabo (2013), Effect of Alternative Scouring Agents on Dyeing Properties Of Cotton/Polyester Blend Fabric. Journal of Applied Chemistry, 5,1121.

[6]. V. B. Gupta and V. K. Kothari (1997), Manufactured Fibre Technology. Chapter 10 Characterization of Polymers and Fibres. (Eds.) Chapman \& Hall. London. 203-247.

[7]. D. E. A. Boryo (2011), Some Effects of Alternative Chemical Treatments on the Mechanical and Dyeing Properties of Cotton/Polyester Blend
Fabric. Unpublished PhD Dissertation Submitted to the Department of Chemistry, ATBU Bauchi.

[8]. N. Poornejad, K. Karimi, and T. Behzad (2013), Improvement of saccharification and ethanol production from rice straw by NMMO and [BMIM][OAc] pretreatments. Industrial Crops and Products 41, 408-413.

[9]. D. E. A. Boryo, K. A. Bello, A. Q. Ibrahim, A. I. Ezeribe, F. I. Omizegba and P. U. Offodile (2013), Effect of Alternative Scouring Agents on Mechanical Properties of Cotton/Polyester Blend Fabric. The International Journal of Engineering and Science, 2, 121-132.

[10]. Y. Yunjie, W. Chaoxia and W. Chunying (2008), An Evaluation of the Dyeing Behavior of Sol-Gel Silica Doped With Direct Dyes. Journal of Sol-Gel Science Technology, 48, 308-314.

[11]. F. Sadov, M. Kauchagin and A. Mastestry (1973), Chemical Technology of fibrous materials. MIR Publishers, Moscow. 22-44, 126-300.

[12]. D. E. A. Boryo, K. A Bello, A.Q. Ibrahim, N. S. Gin, A. I. Ezeribe and K. A. Wasiu (2014), Effects of Alternative Mercerizing Agents on Some Mechanical Properties of Cotton /Polyester Blend Fabric. Academic Journal of Interdisciplinary Studies, 5, 91-103.

[13]. D. E. A. Boryo, K. A. Bello, A. Q. Ibrahim, F. I. Omizegba, G. U. M. Mashat and A. A. Okakwu (2017), Improvement on the Dyeing and Water of Imbibition Properties of Cotton/Polyester Blend Fabric by Alternative Mercerizing Agents. London Journal of Engineering Research, 17, 43-66.

[14]. A, A. El-Ebissy, M. N. Michael and K. E. Shady (2016), Effect of Nano Zinc Oxide on the Structural Characteristic, Tensile Thermal Properties of Textile Fabrics. Journal of Industrial Textile, 46, 130-142. 